\title{
PREVALENCE OF DEPRESSION IN MEDICAL STUDENTS AT RAWAL INSTITUTE OF HEALTH SCIENCES, ISLAMABAD
}

\author{
Uzma Hassan ${ }^{1}$, Naila Azam ${ }^{2}$, Ayesha Farooq ${ }^{3}$, Najm US Saqib Khan ${ }^{4}$
}

${ }^{1}$ Administrator \& Associate Professor Community Medicine Department. Coordinator Medical Education Department. Rawal Institute of health Sciences, Islamabad

${ }^{2}$ Associate Professor and Head of Department. Department of Public Health. Armed Forces Post Graduate Medical Institute, Rawalpindi (AFPGMI)

${ }^{3}$ Professor and Head of Department, Department of Biochemistry Watim Medical and Dental College, Islamabad.

${ }^{4}$ Director General Medical Services (Navy). Naval Headquarters (NHQ), Islamabad.

Correspondence: Uzma Hassan. Email.dr.uzma.hassan@gmail.com

\begin{abstract}
Background: Depression is a common mental disorder, a reason of disability and can lead to suicidal tendency. It is a major contributor to the global burden of disease, causing more than 350 million, all age people suffering from depression. Medical Institute is a stressful and competitive atmosphere so the medical students have to make a lot of personal and social sacrifice to retain respectable educational grades. This pressure may result in an extensive range of psychological ailments like depression, tension and anxiety.

Objective: To determine the prevalence of depression in medical students at Rawal Institute of Health Sciences, Islamabad.

Methods: Descriptive cross-sectional study was conducted over six months using the non-probability convenience method of sampling. Total 100 students from different classes of 1st to 5th year MBBS were included. A close ended questionnaire was used by interview method and response was noted against thirteen study variables related to symptoms of depression. The prevalence of depression in students was calculated based on the ICD-10 criteria; according to which they were categorized as "no depression" having less than four symptoms, "mild depression" having four symptoms, "moderate depression" having four to six symptoms and "severe depression" having seven or more symptoms.

Results: Out of 100 students $55 \%$ students were suffering from depression: among which $15 \%$ were having mild depression, $23 \%$ had moderate depression and $17 \%$ had severe depression. It was more common among female students, residing in hostels.

Conclusion: The results depicted that there is high prevalence of depression in medical students, more among female students. This study sets an important groundwork for more elaborate and extensive future studies. It is recommended that the Institutes should have comprehensive educational programs, regarding preventive measures about mental health syndromes, and implementation of rehabilitative approaches in this regard.
\end{abstract}

Keywords: Prevalence, depression, medical students

\section{Introduction}

World Health Organization has demarcated depression as a common mental disorder, presented by sadness, loss of interest or pleasure, feelings of guilt or low selfworth, disturbed sleep or appetite, feelings of tiredness, and poor concentration (1).

Depression is characterized by a condition of low temper and dislike to activities that can upset an individual's opinions, performance, spirits and sense of security (2). Depression occurs due to the disproportion of neurotransmitters in brain. This could occur due to reasons such as abuse which can be physical, sexual, or emotional (3). Other contributing factors can even be the noble occasions like beginning a new employment, progressing, matrimonial reason and in addition, loss of a career or salary, getting separated, retirement, social isolation, psychological ailment, and being detached from a domestic or societal cluster.

Globally about one third of medical students are affected by Depression but the management and treatment rates very low. These findings were given in the study by Puthran et al(4). They further suggest that medical 
colleges and health authorities should implement early detection and prevention programs. Secondly interventions for depression amongst medical students before graduation should be implemented.

The prevalence of depressive disorders among medical students in Cameroon is high and is associated with the presence of chronic disease, major life events, female gender and being a student at the clinical level. This was reported by Ngasa et al(5) in a study that recommends clinicians attending to medical students suggestive of greater threat of depression, to make comprehensive inquiries on the likely presence of depression

Surbhi et al(6) found that the prevalence of provisionally diagnosed depressive and major depressive disorder using PHQ-9 was $21.5 \%$ and $7.6 \%$, respectively. Year of study and academic performance of students had a statistically significant association with depression. This study showed that prevalence of depression in medical students is high and a same trend has been seen in studies done globally. The medical students are unwilling to seek help for depression. Efforts should be made to decrease the prevalence of this important problem and also to improve their help-seeking attitude.

In study by Basnet et al(7), the overall prevalence of depression among the students was found to be 29.78 percent. The prevalence of depression in first and third year was 36.74 and 22.22 percent respectively. The prevalence of depression was 32.43 percent among female students versus 28.07 percent in male students. Both first and third year students gave the opinion that academic stress and demanding lifestyle are the main factors inducing stress.

Rawat, Kumar and Manju(8) conducted a study with 300 students, out which $42 \%$ had no depression while $43 \%$, $12 \%$ and $3 \%$ had mild, moderate and severe depression respectively. The factors like the year of study, financial stress, extra-curricular activities, substance abuse, family history of depression, family and health related issues were found to have association with depression. Gender and presence of addiction were not found to be associated with depression.

In study by Khan et al(9) among the medical students in Karachi Pakistan, $70 \%$ students were found to have high prevalence of depression. Students using substance abuse, having family history of depression and those who had lost a relative in last one year were more depressed. This study highlighted that there are certain risk factors other than academic stressors which predispose a medical student to psychological morbidity such as anxiety and depression.

Study by Abrar et al(10) on 500 medical students at Shifa College of Medicine, concluded that $39.6 \%$ of students were found to have anxiety and depression. First year medical students were found to have more anxiety and depression (52.6\%). This study highlights the severity of the situation, and necessitate skilled psychiatrists to manage this massive burden of disease.

Anxiety and Depression symptoms were present in
$45.5 \%$ of 437 total students as found by Hashmi et al(11). Factors associated with depression symptoms in multivariate analysis were medical school year, failure in medical school annual examination, number of hours of study, family and past history of depression. This study also concluded that there is a high prevalence of depression and anxiety symptoms in medical students, which have made them making them a highly vulnerable group and high risk group.

A depressed individual may present with the signs and symptoms of feelings of vulnerability and desperateness, loss of attention in daily actions, hunger or weight fluctuations, sleep variations which can be either sleeplessness or hypersomnia, frustration or irritability, loss of vigor, thoughtless conduct, attention difficulties, and inexplicable discomforts and aches(12). Once diagnosing depression, it is documented that it depends on the Criteria for Major Depressive Episode which known as The Diagnostic and Statistical Manual of Mental Disorders (DSM-5). It is the standard taxonomy of mental syndromes used by mental health professionals in the United States. It contains a citation of diagnostic criteria for every psychiatric syndrome which is documented by the U.S. health care organization.

During evaluation of depression; the following five or more symptoms have been noticed during the same two weeks duration and symbolize a modification from previous working; at least one of the symptoms is either disheartened mood or loss of attentiveness or desire.

In addition to the above assessment; the depressed individual may show disheartened mood most of the day, almost every day. It is depicted by either the individual report like feels sad or empty or the remarks made by others like appears tearful. Evidently reduced attention or desire in all, or almost all, actions most of the day. Substantial weight reduction, change in appetite which is present almost every day. Sleeplessness or hypersomnia almost every day. Psychomotor anxiety or interference nearly every day. In addition to these, symptoms like; exhaustion or loss of vigor nearly every day, spirits of unimportance or extreme or unsuitable guilt nearly every day, reduced ability to meditate or focus, or inconclusiveness, nearly every day. Recurring thoughts of death, suicidal tendency without a precise idea, or a suicide effort or a precise idea for compelling suicide(12).

In this research ICD-10 criteria is used to categorize the degrees of depression, as it is the standard criteria by WHO used in majority of the countries. The prevalence of depression can be categorized in different degrees like "No depression", "mild depression", "Moderate depression" and "Severe Depression". The ten different symptoms define the degree of depression and the management is based on the particular degree. Those students who were having less than four symptoms were categorized as "No depression", those having four symptoms were categorized as having "Mild 
Depression", those having four to six symptoms were categorized as "Moderate depression" and those who had seven or more than seven symptoms were labelled in the category of "Severe depression".

Fundamental indications and symptoms include obstinate grief or low temper; loss of interests and pleasure, fatigue or low vigor, at least one of these, which are there for most of the days, and most of the time for at least duration of two weeks.

Once evaluating the person if the above-mentioned symptoms are present, ask about the related symptoms which include bothered sleep, deprived focus or inconclusiveness, low self-assurance, poor or increased appetite suicidal beliefs or actions, anxiety or slowing of actions and guiltiness or self-blame.

Above mentioned ten symptoms define and express the gradation of depressive illness and the further managing strategy and evaluation is centered on the specific gradation. The degrees of depression are defined as: First degree is No depression which less than four symptoms has, second is mild depression having four symptoms, third degree is moderate depression which has five to six symptoms and the last degree is severe depression which has seven or more symptoms, which may be with or without the psychotic symptoms. The symptoms should be existing for a month or more than that and then every symptom should be existing for maximum of every day(2).

Depressive illness is be treated by lifestyle modifications such as exercise, nutrition, sleep, social support and stress reduction. The medical treatment includes the different drugs like selective serotonin reuptake inhibitors, serotonin and norepinephrine reuptake inhibitors, tricyclic antidepressants, monoamine oxidase inhibitors, serotonergic antidepressants and interventions like psychotherapy and social rehabilitation(12).

Prevention includes monitoring of mood swings. Drawing up a list of any warning signs observed, such as insomnia or negative thoughts. Identifying the activities which improve the mood and integrating them into daily activities. A healthy diet, exercise and good sleeping habits as tiredness is aggravated by poor diet. Regular exercise has a positive impact on your mood. Identify the personality traits that could lead into having negative thoughts especially if there is a tendency to perceive circumstances and events in far too negative a light, worry about things unduly, difficulty in expressing your feelings, tend to be inflexible or a perfectionist, a course of psychotherapy would be deemed useful. Stress cannot be avoided but avoiding dealing with it results in an accumulation of stress hence be realistic about the capacity to absorb stress. A good social and support network can act as a buffer against depression. Spending too much time on one's own can contribute to depression and to relapses. Try to have a good work-life balance by ensuring that sufficient time is devoted to work, family, friends and to leisure activities. Above all, talking about ones difficulties to someone who will respect your confidences or to a health professional(3).

\section{Methodology}

This study was a descriptive cross-sectional study, carried out at Rawal Institute of Health Sciences, Islamabad to determine the prevalence of depression in medical students. The duration of the study was six months from April- Oct 2016. The non-probability convenience method of sampling was used. Total 100 students were included, from the Institute from different classes of 1st to 5th year MBBS. Both genders were included. Prior permission was taken from the study subject and confidentiality was assured. Permission was also taken from the ethical review board of the Institute to conduct the study. Before carrying out the actual study, a pilot study was carried out on 20 respondents and then the questionnaire was changed accordingly.

A close ended questionnaire was used by interview method and the response was noted by the researcher in "Yes" and "No" against the thirteen study variables related to depression. The prevalence of depression was noted which was based on the ICD-10 criteria. The students were categorized in "No depression", "mild depression", "Moderate depression" and "Severe Depression". Those students who were having less than four symptoms were categorized as "no depression", those having four symptoms were categorized as having "mild depression", those having four to six symptoms were categorized as "moderate depression" and those who had seven or more than seven symptoms were labelled in the category of "severe depression". The results obtained were calculated as frequencies and shown in percentages and further analyzed through Microsoft Excel.

Already diagnosed cases of depression were excluded from the study. The limitation of study was the convenience sampling, having unequal number of males and female students, and inclusion of different medical years.

\section{Results}

Total 100 students were included in the study and their response was noted against different variables for symptoms of depression (Table 01). The prevalence of depression in medical students was calculated on the basis of ICD-10 criteria (Table 02) where they were categorized as; no depression, mild depression, moderate depression and severe depression. 
Table 1: Variables for symptoms of depression. $(n=100)$

\begin{tabular}{|c|c|c|c|}
\hline \multirow[t]{2}{*}{ S/No } & \multirow[t]{2}{*}{ Variables for symptoms of depression } & \multicolumn{2}{|c|}{$\begin{array}{l}\text { Response noted } \\
n=100\end{array}$} \\
\hline & & Yes & No \\
\hline 1. & $\begin{array}{l}\text { Do you prefer to be alone instead of being } \\
\text { surrounded by people. }\end{array}$ & $\begin{array}{l}47 \\
(47 \%)\end{array}$ & $\begin{array}{l}53 \\
(53 \%)\end{array}$ \\
\hline 2. & $\begin{array}{l}\text { Have you been sad or in low mood for two weeks } \\
\text { or more. }\end{array}$ & $\begin{array}{l}30 \\
(30 \%)\end{array}$ & $\begin{array}{l}70 \\
(70 \%)\end{array}$ \\
\hline 3. & Do you still find your daily activities interesting. & $\begin{array}{l}54 \\
(54 \%)\end{array}$ & $\begin{array}{l}46 \\
(46 \%)\end{array}$ \\
\hline 4. & Do you feel low energy levels. & $\begin{array}{l}37 \\
(37 \%)\end{array}$ & $\begin{array}{l}63 \\
(63 \%)\end{array}$ \\
\hline 5. & $\begin{array}{l}\text { Do you have abnormal sleeping patterns } \\
\text { (increased or decreased) }\end{array}$ & $\begin{array}{l}53 \\
(53 \%)\end{array}$ & $\begin{array}{l}47 \\
(47 \%)\end{array}$ \\
\hline 6. & Do you have poor concentration or indecisiveness & $\begin{array}{l}46 \\
(46 \%)\end{array}$ & $\begin{array}{l}54 \\
(54 \%)\end{array}$ \\
\hline 7. & Do you have low self confidence & $\begin{array}{l}29 \\
(29 \%)\end{array}$ & $\begin{array}{l}71 \\
(71 \%)\end{array}$ \\
\hline 8. & $\begin{array}{l}\text { Do you have disturbed appetite (increased or } \\
\text { decreased) }\end{array}$ & $\begin{array}{l}43 \\
(43 \%)\end{array}$ & $\begin{array}{l}57 \\
(57 \%)\end{array}$ \\
\hline 9. & Do you think about hurting yourself or anyone else & $\begin{array}{l}33 \\
(33 \%)\end{array}$ & \begin{tabular}{|l|}
67 \\
$(67 \%)$
\end{tabular} \\
\hline 10. & $\begin{array}{lll}\begin{array}{l}\text { Do you feel agitated } \\
\text { movements }\end{array} & \text { or experience } & \text { slow } \\
\end{array}$ & \begin{tabular}{|l|}
32 \\
$(32 \%)$
\end{tabular} & $\begin{array}{l}68 \\
(68 \%)\end{array}$ \\
\hline 11. & Do you often feel guilty or blame yourself & $\begin{array}{l}40 \\
(40 \%)\end{array}$ & $\begin{array}{l}60 \\
(60 \%)\end{array}$ \\
\hline 12. & $\begin{array}{l}\text { Are you addicted to any drug or other substance } \\
\text { e.g cigarette, alcohol, sheesha or Marijuana }\end{array}$ & \begin{tabular}{|l|}
11 \\
$(11 \%)$
\end{tabular} & $\begin{array}{l}89 \\
(89 \%)\end{array}$ \\
\hline 13. & Do you have family history of depression & \begin{tabular}{|l|}
14 \\
$(14 \%)$
\end{tabular} & $\begin{array}{l}86 \\
(86 \%)\end{array}$ \\
\hline
\end{tabular}

Out of 100 students 55 (55\%) students were suffering from depression while $45(45 \%)$ students were having no symptoms of depression. Depression was more common among female students.

According to the ICD-10 criteria of depression; 45 (45\%) students were having no depression, $15(15 \%)$ students had mild depression, $23(23 \%)$ students had moderate depression and $17(17 \%)$ students had severe depression.

Table 2: Prevalence of Depression in medical students; according to ICD-10 Criteria $(n=100)$

\begin{tabular}{|l|c|c|}
\hline \multicolumn{1}{|c|}{ Degree of depression } & No of students & Percentages \\
\hline No depression & 45 & $45 \%$ \\
\hline Mild depression & 15 & $15 \%$ \\
\hline Moderate depression & 23 & $23 \%$ \\
\hline Severe depression & 17 & $17 \%$ \\
\hline
\end{tabular}

\section{Discussion}

In this study conducted at Rawal institute to health sciences, Islamabad out of 100 students, 55 (55\%) students were found to be depressed. According to the ICD-10 criteria; $15 \%$ were suffering from mild depression, $23 \%$ from moderate depression and $17 \%$ from severe depression.

The results of this study are found to be significantly higher than the results of BPKIHS, Nepal (29.78\%) and Karolinska Institute Medical University, Stockholm, Sweden $(12.9 \%)$ while it is comparable with the studies conducted at Nishtar medical college, Multan Pakistan (43.89\%) and Wah medical college, Pakistan (35.1\%). The reason might be the different methodology recently introduced by medical education field related to new teaching and assessment methods which include Objective structured performance examination and Problem based learning. Also difference in social, political, environmental and economic factors may contribute to the considerable difference in results.

In females high prevalence of depression is because of the reasons that: first, females complain more about the high load of the curriculum, second, they usually are more bothered about strain due to self-anticipation, sensation of deficiency of proficiency, third, females are more likely to exaggerate and over complaint about physical and psychological indications, and fourth, females face less job chances than males in eastern countries. This may be because of the equality of rights between both genders.

There are numerous demographic, social, academic and behavioral factors which are observed to be linked with depression which commonly are; gender, family history, residence, drug addiction, the inability to share families in social activities, feeling of loneliness, sleep disturbances, prolonged physical illnesses, studying in English language, issues with exams criteria, and the organization of lectures and timetables.

Negative consequences can occur because of depression like medical institute failure, diminished capability to work proficiently, burnout, worsening of relations, and increased affinity of suicide, self-harm and then compound existing problems of provision of health care. So it is very important to give emphasis upon the psychological well- being of medical students.

Anxiety and depression is an important indicator of mental health of an individual, it is a treatable disorder, and commonly present in medical students. It leads to disastrous effects on the physical and mental health of individual that is why it is an important health issue.

The prevalence of depression was high as medical students have to deal with a lot of added stress in addition to normal stress of daily life, which include long duty hours, repeated exposure to traumatic patients, ethical problems, difficult cases, lack of free relaxing time, work and information overload.

Medical students are hesitant to pursue suitable assistance for psychological health issues and consider it as a flaw. So the students should be encouraged to get help for their problems and should also avail the adequate and appropriate medical facilities.

In the Institutes counselling and encouragement should be given to students to give priority to their personal matters and social aspects and guide them about the 
strategies of coping health promotion so that they can effectively deal with their stressors which will reduce the depression.

To facilitate and implement the depression reducing parameters; the recreational facilities should be provided in the Institutes. In the very early years of medical education the Preventive programming efforts should be initiated which should focus on area of concerns including academic, nonacademic, interpersonal relationships and financial problems. The main aspect is to address the early signs and symptoms of depressive illness in the medical scholars.

We need Program implementations and interventions that will aid the students to manage with stress. This in turn will make a suave evolution from school to medical college and regulate to various challenging educational surroundings during the various stages of medical training. Our research motivates new educational approach to minimize stress and hence depression in the medical students.

\section{Conclusion}

The results depicted that there is a high prevalence of depression in medical students, more among female students. This study sets an important groundwork for more elaborate and extensive future studies. It is recommended that the Institutes should have comprehensive educational programs, regarding the preventive measures about mental health syndromes, and implementation of rehabilitative approaches in this regard. Students should be educated about the importance of depression and encouraged to seek psychiatric attention if they are experiencing any signs and symptoms of depression.

Extracurricular facilities should be provided to the students in addition to advising them to maintain a healthy social life. Students should be motivated to have balanced diet, do exercise and spare time for relaxation and enjoyment.

Screening can be done especially near the exams, to evaluate development of any depressive symptoms.

Professional attitudes and institutional policies should be modified and improved to encourage students to seek help.

\section{References}

1. Mental Health - Depression: let's talk [Internet]. World Health Organization. Available from: www.who.int

2. American Psychiatric Association, American Psychiatric Association, editors. Diagnostic and statistical manual of mental disorders: DSM-5. 5th ed. Washington, D.C: American Psychiatric Association; 2013.947 p.

3. Common Causes of Depression [Internet]. WebMD. Available from: www.webmd.com

4. Puthran R, Zhang MW, Tam WW, Ho RC. Prevalence of depression amongst medical students: a meta-analysis. Med Educ. 2016;50(4):456-468.
5. Ngasa SN, Sama C-B, Dzekem BS, Nforchu KN Tindong $M$, Aroke $D$, et al. Prevalence and factors associated with depression among medical students in Cameroon: a crosssectional study. BMC Psychiatry. 2017;17(1):216.

6. Sidana S, Kishore J, Ghosh V, Gulati D, Jiloha $\mathrm{RC}$, Anand T. Prevalence of depression in students of a medical college in New Delhi: a cross-sectional study. Australas Med J. 2012;5(5):247.

7. Basnet B, Jaiswal M, Adhikari B, Shyangwa PM. Depression among undergraduate medical students. Kathmandu Univ Med J. 2013;10(3):56-59.

8. Rawat R, Kumar S, Manju L. Prevalence of depression and its associated factors among medical students of a private medical college in south India. Int J Community Med Public Health. 2017;3(6):1393-1398.

9. Khan MS, Mahmood S, Badshah A, Ali SU, Jamal Y. Prevalence of depression, anxiety and their associated factors among medical students in Karachi, Pakistan. J-Pak Med Assoc. 2006;56(12):583.

10. Abrar A, Kazim M, Hanif M, Mansoor S, Tahir S, Makken $\mathrm{N}$, et al. Prevalence of anxiety and depression among medical students of shifa college of medicine. Pak J Neurol Sci PJNS. 2014;9(3):12-15.

11. Hashmi AM, Aftab MA, Naqvi SH, Sajjad W, Mohsin M, Khawaja IS. Anxiety and depression in Pakistani medical students: A multi-center study. Health Med. 2014;8(7):813-20.

12. Depression Symptoms and Warning Signs [Internet]. HELPGUIDE.ORG Trusted guide to mental \& emotional health. Available from: www.helpguide.org 